\title{
Unlicensed and off label drug use in neonates
}

\author{
Sharon Conroy, John McIntyre, Imti Choonara
}

\begin{abstract}
Aim-To determine the extent of use of drugs that are either not licensed (unlicensed), or are outside the terms of their product licence (off label) in a neonatal intensive care unit.

Methods-A prospective study was conducted over 13 weeks.

Results-455 prescription episodes were administered to 70 babies. $63(90 \%)$ patients were given a drug that was either unlicensed or used in an off label way. $54.7 \%$ prescription episodes were off label, many for more than one reason, and $9.9 \%$ (45) were unlicensed; $35.4 \%$ (161) prescription episodes were licensed.

Conclusion-The use of unlicensed and off label drugs in neonatal intensive care seems to be far greater than other paediatric settings. This highlights the difficulties faced by those trying to ensure safe and effective prescribing for neonates. Urgent action is required to resolve this situation. (Arch Dis Child Fetal Neonatal Ed 1999;80:F142-F145)
\end{abstract}

Keywords: unlicensed/off label drug use; intensive care

Drugs are subject to licensing procedures to ensure their safety, effectiveness, and quality. Many drugs used to treat children in hospital are either not licensed (unlicensed), or are prescribed outside the terms of the product licence (off label). ${ }^{12}$

Despite widespread interest in the licensing of medicines in children, there is little information available on the extent of unlicensed and off label drug use in this age group, particularly in neonates. ${ }^{12}$ This study was designed to assess the extent and nature of unlicensed and off label drug use in a neonatal intensive care unit in a district general hospital.

\section{Methods}

A data collection form was designed and used by the clinical research pharmacist (SC) to gather information prospectively from prescriptions for all patients admitted to neonatal intensive care for 13 weeks from February to May 1998. Details recorded included: patient's hospital number, date of birth, weight, gestation, diagnosis, drugs administered, date and route of administration, dose, frequency and indication for use. As in previous studies, ${ }^{2}$ the use of the following drugs was not recorded: standard intravenous replacement solutions, flushes of sodium chloride $0.9 \%$ or heparin to maintain the patency of intravenous and arterial lines, blood products (other than albumin) and oxygen therapy.

All drugs administered were assessed by SC for unlicensed or off label use using a classification system described and used in previously published studies. ${ }^{3}$

Categories of unlicensed drugs identified included:

- Modifications to licensed drugs. An example of this is the preparation of a total parenteral nutrition infusion by a hospital pharmacy aseptic service unit.

- The use of "special" formulations of licensed drugs produced under a manufacturing licence. An example is a suspension of a drug licensed in a solid dose form but formulated into a liquid preparation by a "specials" manufacturer-for example, dexamethasone.

- "New" drugs produced under a specials manufacturing licence. These drugs have often been used for many years but have never undergone formal clinical trials or been subject to the licensing regulations and therefore have no product licence. An example is tolazoline injection for the treatment of pulmonary hypertension in neonates.

Off label categories included the administration of a drug to patients of an age not covered by the product licence, in a dose other than that specified in the licence, by an alternative route or for an indication not included in the licence. The primary reference source used was the Data Sheet Compendium 1998-99 produced by the Association of the British Pharmaceutical Industry. ${ }^{4}$ Alternative sources of information used included the package insert from certain products and the British National Formulary March $1998^{5}$ as most information in these sources conforms to that in a drug's data sheet. The manufacturer of the product was contacted where other information could not be found or was ambiguous.

\section{Results}

Seventy patients were admitted to neonatal intensive care during the study period. Forty nine babies were premature, requiring intensive care; the median gestational age in this group was 33 weeks (range 26 to 36 weeks). Twenty one babies were term (37 or more weeks gestation) and required intensive support due to suspected sepsis $(n=6)$, hypoglycaemia $(n=5)$, transient tachypnoea of the new born $(n=3)$, congenital heart defects $(n=2)$, neonatal abstinence syndrome $(n=2)$, seizures $(n=1)$, meconium aspiration $(n=1)$, or respiratory distress $(n=1)$.

The babies received a total of 455 prescription episodes (each episode being a course of a drug or a single one off dose). The number of prescription episodes per patient ranged from 0 to 42 , the median being 3.5 . The 10 most commonly administered drugs are shown in table 1. 
Table 1 Ten most commonly prescribed drugs in neonatal intensive care

\begin{tabular}{ll}
\hline Drug & $\begin{array}{l}\text { No (\%) of prescription } \\
\text { episodes }(n=455)\end{array}$ \\
\hline Gentamicin & $49(10.8)$ \\
Benzylpenicillin & $48(10.5)$ \\
Folic acid & $32(7)$ \\
Dalivit & $31(6.8)$ \\
Albumin & $30(6.6)$ \\
Vitamin K & $26(5.7)$ \\
Frusemide & $26(5.7)$ \\
Caffeine & $18(4)$ \\
Flucloxacillin & $16(3.5)$ \\
Morphine & $13(2.9)$ \\
\hline
\end{tabular}

One hundred and sixty one $(35.4 \%)$ of the prescriptions were licensed drugs used in a licensed way. Forty five $(9.9 \%)$ were unlicensed drugs and the remaining 249 (54.7\%) episodes were drugs used in an off label way. Sixty three $(90 \%)$ babies received at least one unlicensed or off label drug.

The unlicensed drugs fell into three categories as shown in table 2 . The off label drugs can be classified as shown in table 3 .

Off label use is far more common than unlicensed drug use in this population. The most commonly administered unlicensed and off label drugs in this study are shown in table 4 . It includes nine of the 10 most frequently prescribed drugs used in neonatal intensive care (table 1, all except frusemide).

Thirteen prescription episodes were unlicensed and off label. This apparently contradictory statement is explained by the fact that these were all intravenous infusions of drugs prepared in a ready to administer form by the Pharmacy Department Aseptic Services Unit, thus rendering them unlicensed preparations. The drugs involved were morphine and dopamine. As these are not recommended for use in neonates they were off label for age.

Table 2 Unlicensed drug categories

\begin{tabular}{ll}
\hline & $\begin{array}{l}\text { No of } \\
\text { prescription } \\
\text { episodes (\%) } \\
(n=455)\end{array}$ \\
Unlicensed category & $21(4.6)$ \\
\hline Modification to a licensed drug & 11 \\
Morphine & 6 \\
TPN & 3 \\
Phenobarbitone & 1 \\
Dopamine & \\
(All prepared in pharmacy) & \\
"New" drug prepared by "specials" & $18(4)$ \\
manufacturer & 18 \\
Caffeine & $6(1.3)$ \\
"Special" formulation of licensed drug & 3 \\
Chloral hydrate & 1 \\
Dexamethasone & 1 \\
Adrenaline & 1 \\
Spironolactone & \\
Total number of unlicensed prescription & $45(9.9)$ \\
episodes &
\end{tabular}

Table 3 Off label drug categories

\begin{tabular}{ll}
\hline Reason for drug being off label & $\begin{array}{l}\text { No of prescription } \\
\text { episodes }(n=455)\end{array}$ \\
\hline Outside dose recommendations & 182 \\
(High) & $(86)$ \\
(Low) & $(96)$ \\
Used for non-licensed indication & 68 \\
Outside licensed age range & 63 \\
Used by unlicensed route & 24 \\
Total number of off label episodes & 337 \\
\hline
\end{tabular}

Table 4 Most commonly prescribed off label and unlicensed drugs

\begin{tabular}{lll}
\hline & $\begin{array}{l}\text { No of off } \\
\text { label/unlicensed } \\
\text { prescription } \\
\text { episodes }(n=455)\end{array}$ & Status \\
\hline Benzylpenicillin & 46 & Off label dose \\
Folic acid & 31 & Off label dose/indication \\
Dalivit & 30 & Off label dose/age \\
Vitamin K & 23 & Off label dose \\
Caffeine & 18 & Unlicensed - 'special' \\
Flucloxacillin & 16 & Off label dose \\
Albumin & 15 & Off label indication \\
Gentamicin & 15 & Off label dose \\
Morphine & 12 & Off label age/unlicensed \\
Glycerin & 9 & Off label route/indication \\
Cyclopentolate & 7 & Off label age \\
Sodium chloride & 6 & Off label route \\
TPN & 6 & Unlicensed- \\
& & made in pharmacy \\
\hline
\end{tabular}

Seventy six prescription episodes were off label for two reasons. An example is Dalivit multivitamin drops that are started on day 10 in a dose of 14 drops daily, according to this neonatal intensive care unit policy. They are licensed from six weeks of age at a dose of 7 drops daily. In our unit they are therefore used off label for age and dose.

\section{Discussion}

Previous studies in a regional children's hospital have described unlicensed and off label drug use in a paediatric intensive care unit, and on paediatric medical and surgical wards. ${ }^{12}$ On a paediatric intensive care unit $31 \%$ of prescription episodes were unlicensed or off label drugs and $70 \%$ of patients received at least one unlicensed or off label drug. ${ }^{1}$ On paediatric wards $25 \%$ of prescriptions were unlicensed or off label and $36 \%$ of patients received at least one unlicensed or off label drug. ${ }^{2}$ The overall incidence was similar on the medical and surgical wards studied. This study shows that unlicensed and off label drug use in the neonatal intensive care setting is far greater than in older children.

Information in the product licence is designed to ensure safe, effective prescribing. Our study indicates many prescriptions in neonatal intensive care are off label - that is, given in a way not covered by the product licence. This highlights the inadequacies of the current licensing framework.

Dose recommendations for children, and neonates in particular, are often unreliable for safe prescribing. The commonest drug prescribed in this study was gentamicin injection, a drug used routinely in many neonatal centres. Manufacturers of gentamicin injection recommend doses of $2.5-3 \mathrm{mg} / \mathrm{kg} /$ dose given twice daily for the first 7-14 days of life. Gentamicin is renally excreted, and at birth renal function is limited due to the anatomical and functional immaturity of the kidney. Glomerular filtration rate may be as low as $0.6-0.8 \mathrm{ml} / \mathrm{min}$ in preterm infants, depending on postconceptional age and prenatal exposure to drugs such as steroids and indomethacin. ${ }^{6}$ To account for this our neonatal intensive care policy is to give $2.5 \mathrm{mg} / \mathrm{kg} /$ dose at dosing intervals determined by postconceptional age-for example, 18 hourly or 24 hourly (an off label dose). If 
licensed doses were used, premature babies would be exposed to excessive serum concentrations of this highly toxic drug. ${ }^{7}$

The prescriber may also find the recommendations of the product licence and current prescribing practices at variance. Benzyl penicillin was the second most commonly prescribed drug in our study used in a dose of 120 $\mathrm{mg} / \mathrm{kg} /$ day for neonates under 7 days of age, and $240 \mathrm{mg} / \mathrm{kg} /$ day thereafter. The licensed dose in newborn infants is normally $50 \mathrm{mg} / \mathrm{kg} /$ day, $100 \mathrm{mg} / \mathrm{kg} /$ day if meningitis is suspected, increasing to $150 \mathrm{mg} / \mathrm{kg} /$ day after the first week of life. The high off label dose in the neonatal intensive care policy is used because of concerns regarding group B streptococcal sepsis. ${ }^{8}$ Commonly used references for neonatal prescribing, such as the Alder Hey Book of Children's Doses or the Guy's, St Thomas' and Lewisham Hospitals Paediatric Formulary, all contain different doses which poses a dilemma for clinicians when trying to ensure safe and effective prescribing.

Evidence based practice is advocated in all areas of patient care, but as this study shows it is certainly not the norm in the treatment of the neonatal population. Vitamin $\mathrm{K}$ is administered to all babies at birth. In this hospital some babies receive it in the delivery room and therefore these figures are not included in the number of drugs administered in the neonatal intensive care unit. Vitamin $\mathrm{K}$ has been given to most newborn babies in the UK for the past 50 years. Yet only in the past decade have there have been controlled clinical trials of sufficient statistical power to determine the minimum effective dose and duration of treatment. ${ }^{910}$ In our unit a dose of $250 \mu \mathrm{g}$ is given by the intramuscular route to all babies who require admission to intensive care. In light of current doubt regarding the safety of the drug, neonatologists are understandably reluctant to increase to the licensed dose of $1 \mathrm{mg}$, therefore all these babies receive an off label dose.

The licensing process was established under the Medicines Act of 1968 after toxic effects were found in fetuses and neonates exposed to certain drugs. These included the use of thalidomide in pregnancy, resulting in phocomelia, an effect of a drug on the developing fetus. Chloramphenicol caused grey baby syndrome and deaths in neonates due to doses which exceeded the underdeveloped hepatic metabolism of the neonate. Neonates, with their immature hepatic and renal function, rapid growth, continual changes in capacity to handle drugs, and unpredictable sensitivity to drugs are likely to be more susceptible to toxic effects than any other identifiable population. These physiological factors are compounded by the lack of trials to provide accurate pharmacokinetic data on which to base dose recommendations, leading to estimations based on extrapolation from adult parameters. As the technology to save babies at earlier gestations progresses, careful, well designed and conducted clinical trials are essential if further serious adverse drug reactions are to be avoided.
In conclusion, we have shown that on a neonatal intensive care unit most prescriptions are either off label or unlicensed, with only $35 \%$ of prescription episodes licensed. The problem of licensing of drugs in children has recently been addressed by the publication of new guidance on clinical investigation of medicinal products in children that came into force in September 1997. ${ }^{11}$ This is an excellent step forward, which hopefully will be taken seriously by the pharmaceutical industry to help resolve the difficulties clinicians have prescribing for children generally, and the newborn infant in particular. There is also clearly a need for the Department of Health to take a major interest in this area.

1 Turner S, Gill A, Nunn T, Choonara I. Use of 'off label' and unlicensed drugs in paediatric intensive care unit. Lancet 1996;347:549-50.

2 Turner S, Longworth A, Nunn AJ, Choonara I. Unlicensed and off label drug use in paediatric wards: prospective study. BMF 1998;316:343-5.

3 Turner S, Nunn AJ, Choonara I. Unlicensed drug use in children in the UK. Paediatric and Perinatal Drug Therapy. 1997;1:52-5.

4 Association of the British Pharmaceutical Industry. ABPI Compendium of data sheets and summaries of product characteristics 1998-99. London: Datapharm Publications, 1998.

5 British Medical Association and Royal Pharmaceutical Society of Great Britain. British National Formulary No 34. Lociety of Great Britain. British
London: BMA, RPSGB, 1997.

London: BMA, RPSGB, 1997.
6 Van den Anker JN. Pharmacokinetics and renal function in preterm infants. Acta Paediatr 1996;85:1393-9.

7 Buss WF. Letter to the Editor. F Ped Pharm Pract 1997;2:336-7.

8 Baker CJ. Group B Streptococcal infections. Clin Perinatol 1997;24:59-70.

9 Cornelissen EAM, Kollee LAA, De Abreu RA, et al. Effects of oral and intramuscular vitamin $\mathrm{K}$ prophylaxis on vitamin $\mathrm{K}$, PIVKA-II, and clotting factors in breast fed infants. Arch Dis Child 1992;67:1250-4.

10 Cornelissen EAM, Kollee LAA, De Abreu RA, et al. Prevention of vitamin $\mathrm{K}$ deficiency in infancy by weekly Prevention of vitamin K deficiency in infancy by weekly
administration of vitamin K. Acta Paediatr 1993;82:656-9. 11 Note for guidance on clinical investigation of medicinal products in children. London: Medicines Control Agency, 1997.

\section{Commentary}

What is written in the manufacturers' data sheets and summaries of product characteristics about medicinal products, and what is recommended in the standard text books on paediatrics and current formularies on medicinal drugs for children, indicates that many doctors must be prescribing medicines to be given in ways and for conditions not stated in the licence.

The problems of the use of medicines for children outside the licensed indications were outlined in a Joint Report of the then British Paediatric Association and the Association of the British Pharmaceutical Industry: Licensing Medicines for Children. ${ }^{12}$ This report made recommendations with respect to future clinical trials on children, age bands, surveillance of unlicensed use, and the interpretation and clear presentation of whatever information is available. When the Select Committee on Health learnt of the problems they wrote in their 1997 report on child health ${ }^{13}$ :

"We share the view of the working party that the current situation in regard to the testing and licensing of medicines for children is unacceptable. Indeed, we were astonished to discover that this situation existed, and we imagined that most members of the public would share our reaction. We must emphasise that it would be wrong to assume that 
unlicensed or 'off label' medicines are likely to be harmful to children, or that they do not, in the great majority of cases, perform a valuable therapeutic function. The Medicines Control Agency told us that they have 'no evidence that any children have suffered harm as a result of a lack of child specific testing and licensing,' and children are almost certainly the beneficiaries of taking these medicines. But in the absence of a satisfactory system of testing and licensing, we cannot know that this is the case, nor can we know of the small minority of cases-possibly a very tiny minority - where children have suffered actual harm taking such medicines. It is surely wrong that clinicians dealing with children should be put in this position, as they frequently are, of having to guess what an appropriate dosage or route of administration might be. For this reason we strongly support the conclusions of the BPA/APBI working party and urge both the $\mathrm{DoH}$ and the other bodies concerned to accept and implement its recommendations."

How did this situation develop? The MCA was set up under the Medicines Act to ensure that all medicines sold or supplied in the UK meet acceptable standards of safety, quality, and efficacy. The MCA has stated that its primary objective is to safeguard public health by doing just that. They have interpreted "supplied" to mean supplied by manufacturers. Some reading the Medicines Act might think that what is intended is the control of those medicines "supplied" to patients. The MCA controls the claims made by the manufacturers in the summary of product characteristics and data sheet. These state when the medicinal product is indicated and how much should be given. The information must be supported by clinical trials. But it is more difficult to perform clinical trails on children than it is on adults. Often the difficulties are insuperable. This forces clinicians to determine when to use a medicine and in what dose based on what they know of how the medicine works, clinical studies on adults, and what they have learnt from others.

You would have thought that the authorities would think it important to know how extensive the practice of using medicinal products outside their licensed indications was.
Indeed, it could be argued that this is information which should be collected routinely. It is not surprising to learn from Conroy's study that most infants in the neonatal special care unit studied were given medicines off licence, but it is perhaps astonishing to discover that as far as the authors are aware, they are the first to make such observations. The Medicines Act became law after the thalidomide catastrophe. Now, many years later, very immature infants are being given medicines which are not subject to either the monitoring or the control of the authorities set up under the Act.

In this situation, at least in the short term, it seems to me that the only way to protect the best interests of the children is for the professions as a whole, those who prescribe, dispense, or administer drugs to infants and children, to identify the problems, collect the information, and keep each other informed through an agreed formulary. There are already several excellent hospital formularies available in the UK. To set up the network, the Royal College of Paediatrics and Child Health and the Neonatal and Paediatric Pharmacists Group, with the help of many of their members and the support of the Nuffield Foundation, are producing a statement Medicines for Children which will list the current prescribing and dispensing practices in the UK and will identify the unlicensed and off label use of medicinal products in children. This opening statement is expected to be published by the spring of next year, in the hope that it will be the foundation for the wider exercise of evaluation and control. Medicines given to children will then be subject to inquires of similar vigour, relating to efficacy, safety, quality, cost and practicability as those applied to medicines supplied to adults.

\section{Lanark Close}

PROFESSOR SIR DAVID HULL

Nottingham NG8 $1 B Q$

12 BPA/ABPI. Licensing Medicines for Children. Joint Report. British Paediatric Association and the Association of British Pharmaceutical Industry. London: BPA/ABPI, 1996.

13 The Specific Health Needs of Children and Young People. Second Report. House of Commons Health Committee. Vol 1. 1997. 